\title{
A creatinine-based model to predict recurrent bleeding after modified percutaneous transhepatic variceal embolization in cirrhotic patients
}

Zhen Li ( $D$ Izlyct620@163.com )

Kun Ji

Zhengzhou University First Affiliated Hospital

Han-Long Zhu

Nanjing Medical University Second Affiliated Hospital

\section{Si Zhao}

Nanjing Medical University Second Affiliated Hospital

Xin Li

Zhengzhou University First Affiliated Hospital

\section{Peng-Chao Zhan}

Zhengzhou University First Affiliated Hospital

\section{Yang Shi}

Zhengzhou University First Affiliated Hospital

\section{Shu-Wen Ye}

Zhengzhou University First Affiliated Hospital

\section{Bing-Can Xie}

Zhengzhou University First Affiliated Hospital

\section{Yu-Yuan Zhang}

Zhengzhou University First Affiliated Hospital

\section{Peng Yu}

Zhengzhou University First Affiliated Hospital

\section{Zhi-Gang Ren}

Zhengzhou University First Affiliated Hospital

Juan Ding

Zhengzhou University First Affiliated Hospital

\section{Xin-Wei Han}

Zhengzhou University First Affiliated Hospital

Research article 
Keywords: Esophagogastric varices, Percutaneous transhepatic variceal embolization, Risk factors, Nomogram, Prediction

Posted Date: November 13th, 2020

DOI: https://doi.org/10.21203/rs.3.rs-106379/v1

License: (1) This work is licensed under a Creative Commons Attribution 4.0 International License. Read Full License 


\section{Abstract}

Background: Patients who survived the initial esophagogastric variceal bleeding (EVB) experienced an increased risk of recurrent bleeding and death, but a reliable predictive model is lacking. We aim to develop and validate a model for rebleeding prediction in cirrhotic patients with EVB after modified percutaneous transhepatic variceal embolization (PTVE) with cyanoacrylate.

Methods: A total of 122 patients with EVB who underwent PTVE from January 2015 to March 2020 were enrolled in this study. The multivariate logistic analyses were conducted to determine independent risk factors for nomogram construction. The discrimination, calibration and clinical utility of the nomogram were compared with the Model for End-stage Liver Disease (MELD) and Child-Pugh model. Additionally, a risk stratification was developed according to nomogram.

Results: Rebleeding within 3 months after PTVE occurred in 32 patients (26.2\%). The independent rebleeding indicators included the history of endoscopic therapy, Child-Pugh score, partial splenic embolization and creatinine level. The nomogram incorporating these four predictors achieved excellent calibration and discriminatory abilities with a concordance index of 0.85 which was confirmed to be 0.83 through bootstrapping validation. The nomogram harbored better discrimination and clinical applicability than the MELD and Child-Pugh model. As shown in the Kaplan-Meier curves, the patients at high risk were significantly associated with the high probability of rebleeding $(P<0.001)$.

Conclusions: We created a creatinine-based nomogram to predict rebleeding in cirrhotic patients received PTVE, which could help clinicians to discern the high-risk patients to perform more aggressive treatments earlier and formulate intensive follow-up plan for them.

\section{Background}

Esophagogastric variceal bleeding (EVB) occurs in $25-40 \%$ of cirrhotic patients with a mortality of 25$30 \%$, representing a leading cause of death in patients with portal hypertension ${ }^{1,2}$. Reports have revealed that patients who survived the first hemorrhage experienced a high risk of recurrent variceal bleeding, which was significantly associated with an increased risk of death ${ }^{3,4}$. Therefore, researches focusing on the various risk factors of rebleeding are of great significance to identify the high-risk patients.

Currently, endoscopic therapy including sclerotherapy and band ligation is recommended as the standard of care for EVB, and transjugular intrahepatic portosystemic shunt (TIPS) has emerged as an effective modality in secondary control of variceal bleeding ${ }^{5}$. However, the complications of TIPS including the low primary patency rate and the increased risk of $\mathrm{HE}$ also restricts its use in clinical practice ${ }^{6}$. As for those who failed endoscopic therapy, modified percutaneous transhepatic variceal embolization (PTVE) with cyanoacrylate remains a rescue therapy to achieve hemostasis. To date, only a few studies have identified the independent predictors of rebleeding after cessation of initial EVB in cirrhotic patients treated by PTVE ${ }^{7,8}$. The Model for End-stage Liver Disease (MELD) score and Child-Pugh classification 
have been widely recognized as factors predictive of rebleeding after initial EVB ${ }^{9}$. However, the ChildPugh classification only divides patients into high, intermediate and low risk but fails to quantify an expected probability of rebleeding; and the MELD calculation is too complicated to easily obtain the score. To the best of knowledge, this study is the first attempt to generate a predictive nomogram for the unselected cirrhotic patients with EVB treated by PTVE, which can simply predict the specific probability of rebleeding.

The present study aimed to identify the risk factors and to establish a model to predict 3-month rebleeding for cirrhotic patients with EVB treated by modified PTVE as a rescue treatment after failing endoscopic therapy. Additionally, high-risk patients for rebleeding was discerned based on the nomogram to consider administering TIPS or liver transplantation earlier and intensive follow-up plan.

\section{Materials And Methods}

\section{Patients}

Patients who were diagnosed with EVB and received modified PTVE in our hospital from January 2015 to March 2020 were enrolled in this study. The inclusion criteria were as follows: (1) diagnosis of liver cirrhosis by clinical examination and imaging techniques, including ultrasounds, CT, or MRI; (2) gastroscopy confirmed that esophageal varices were the only potential source of bleeding; (3) PTVE was conducted as a rescue therapy in patients who had uncontrolled severe bleeding or recurrent episode of bleeding from varices after pharmacological and endoscopic therapy, such as sclerotherapy and band ligation; (4) patients without catheterizable gastrorenal shunts who could not be treated by balloonoccluded retrograde transvenous obliteration. The exclusion criteria were as follows: (1) severe hypertension, coronary heart disease, cardiopulmonary insufficiency, or chronic renal insufficiency; (2) a history of TIPS creation, pericardial devascularization or splenectomy for varices; (3) patients who died during the current hospitalization; (4) incomplete data on medical records or follow-up. The flowchart of the enrolled patients is shown in Fig. 1. This study was approved by the Ethics Committee Board of the First Affiliated Hospital of Zhengzhou University and in accordance with the Declaration of Helsinki (1989) of the World Medical Association. Informed consent was obtained from all individual participants included in the study.

\section{Treatment}

On admission, all of the patients were treated by an infusion of vasoactive drugs for $72 \mathrm{~h}$ and prophylactic antibiotics for 7 days, and endoscopy within the first $24 \mathrm{~h}$ of hospitalization. PTVE with or without partial splenic embolization (PSE) was performed as a rescue therapy in patients who failed the pharmacological and endoscopic treatment. The procedures were conducted by two interventional radiologists with 15 and 25 years of experience for all cases.

After a percutaneous transhepatic puncture of a branch of the portal vein under digital subtraction angiographic guidance (Artis zeego, Siemens), a 5-F Cobra catheter (Cook) was introduced into the portal 
venous system and a splenoportography was conducted to evaluate the location of the index varices, the feeding vessels, draining veins and the possible presence of gastrorenal shunt. Then the catheter was advanced into each of main feeding vessel (e.g., the left gastric vein, short gastric vein, or coronary gastric vein) to embolize the vascular trunk using coils (3-10 mm $\times 5-12 \mathrm{~cm}$; Cook) or microcoils (2$3 \mathrm{~mm} \times 2-3 \mathrm{~cm}$; Cook). Subsequently, cyanoacrylate was slowly injected to occlude the vascular bed until angiography verified that the blood flow in the varices were completely obstructed. Splenoportography was repeated to assess the extent of variceal obliteration. If other feeding veins were available, the above steps would be repeated until the blood flow in the varices ceased absolutely. Ultimately, the catheter was withdrawn and the puncture tract was embolized with microcoils.

PSE was performed 5-7 days after PTVE in patients who were willing to receive PSE. Briefly, using a transfemoral approach, splenic arterial angiography was implemented using a 5-F RH catheter (Cook) to demonstrate the distribution of splenic arteries. The catheter was inserted into the middle and lower brands of the splenic arteries, and 350-560 $\mu$ m of Polyvinyl alcohol particles (ALICON Pharm SCI \& TECH) mixed with contrast media were carefully injected into the splenic arteries through the catheter. Splenic arterial angiography was repeated to estimate the degree of splenic infarction which was limited to approximately $50-70 \%$ of the original splenic volume ${ }^{10}$.

\section{Data Collection And Follow Up}

All of the patients underwent complete medical assessment at admission, including collection of demographic information, medical history, physical examination, clinical symptoms, ascites, concomitant HCC, degree of splenomegaly, encephalopathy and portal vein thrombosis. Blood for laboratory testing [complete blood count, international normalized ratio (INR), total bilirubin, albumin, aspartate aminotransferase (AST) and serum creatinine] was also collected. The Child-Pugh and MELD scores ${ }^{11}$ were calculated from data recorded upon patient admission.

Rebleeding was defined according to the Baveno criteria ${ }^{12}$ as recurrent hemorrhage proven by new melena or hematemesis, requirement for $>2$ units of packed red blood cell in a $24 \mathrm{~h}$ period and hemodynamic instability after a $24 \mathrm{~h}$ period of stable vital signs and hemoglobin after PTVE. Time to rebleeding was referred to the duration from the eradication of varices hemorrhage to recurrent bleeding. Patients who suffered from recurrent bleeding within 3 months after PTVE were classified as the rebleeding group, and remaining patients as the non-rebleeding group. The patients were followed up in the outpatient clinic or by telephone at 1, 3, 6 and 12 months or until death, loss to follow-up, or the cutoff date for data analysis (June 2020).

\section{Nomogram Construction And Validation}

The univariate and multivariate logistic regression analyses were conducted to screen out the independent risk factors that significantly affected rebleeding. Based on the identified independent risk factors, a nomogram was constructed to predict the probability of 3-month rebleeding after PTVE. 
The nomogram's performance was evaluated using the concordance index (C-index), receiver operating characteristic (ROC) curve, calibration curve and decision curve analysis (DCA). The C-index is defined as

the proportion of all evaluable patient pairs whose predictions are consistent with the actual results ${ }^{13}$. The nomogram was subjected to bootstrapping validation (1,000 bootstrap resamples) to compute a relatively corrected $\mathrm{C}$-index ${ }^{14}$. The nomogram's discrimination and clinical application value were measured utilizing the area under ROC curve (AUC) and $D_{C A}{ }^{15}$ to certify whether the nomogram is superior to the MELD and Child-Pugh models. The calibration of the nomogram was assessed by a calibration curve that compares nomogram-predicted and actually-observed estimates of rebleeding probability. Kaplan-Meier (K-M) curve was constructed to analyze the difference in rebleeding between the high- and low-risk groups based on the nomogram.

\section{Statistical Analysis}

All of the statistical analyses were conducted employing the SPSS software (version 21, IBM Corporation, Armonk, NY, USA) and the programming language R (version 3.6.2) for Windows. The Student's t-test and the Chi-square test, for the continuous and categorical variables respectively, were used to evaluate the association between the rebleeding and variables, by comparing the rebleeding and non-rebleeding groups. Subsequently, the variables with a $P$-value below 0.05 in univariate analysis were selected for entering multivariate logistic regression analysis to ascertain the independent risk factors for rebleeding adopting the forward stepwise selection method. The optimized cut-off values for equally important sensitivity and specificity of INR, creatinine, aspartate aminotransferase, albumin, bilirubin and the total scores calculated from the nomogram were determined using ROC curve. The nomogram, C-index, ROC curve, calibration curve, DCA curve and K-M curve were generated in R with packages "rms", "Hmisc", "ROCR", "Survminer", "survival" and "rmda". Statistical significance was set as P『0.05 in a two-sided test.

\section{Results}

\section{Patient Characteristics}

Among 122 patients, more than two-thirds had virally induced cirrhosis. HCC and portal vein thrombosis were present in $22.1 \%$ and $15.6 \%$ of the patients, respectively, and PSE was carried out in $48.4 \%$ of the patients. Hematemesis and/or melena were the main clinical symptoms of hemorrhage in all cases. There were 32 patients in the rebleeding group and 90 in the non-rebleeding group. The median follow-up time was 6.7 months (3-12 months). More details on patient characteristics are shown in Table 1. 
Table 1

Clinical and biological characteristics of patients on admission

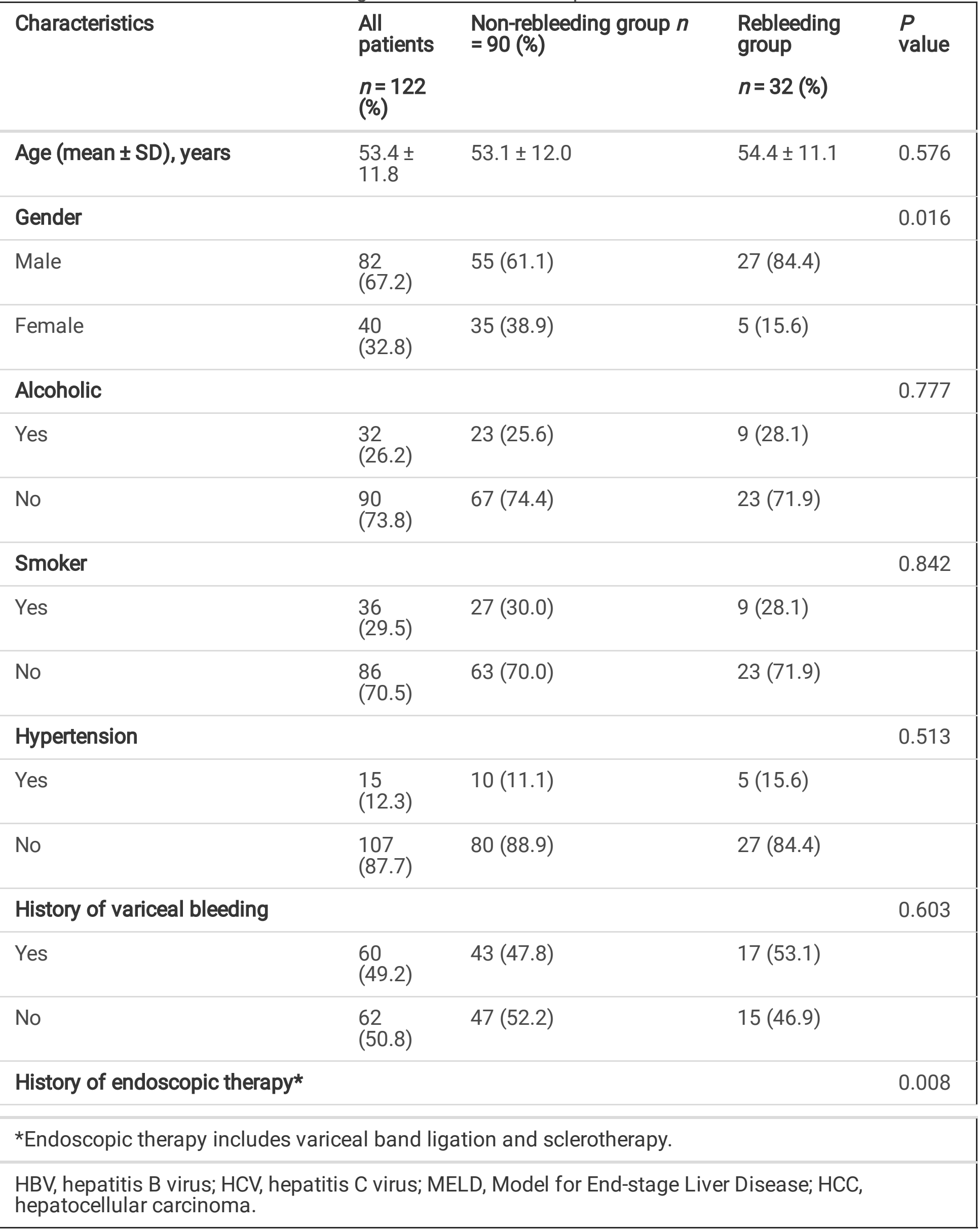




\begin{tabular}{|c|c|c|c|c|}
\hline Characteristics & $\begin{array}{l}\begin{array}{l}\text { All } \\
\text { patients }\end{array} \\
n=122 \\
(\%)\end{array}$ & $\begin{array}{l}\text { Non-rebleeding group } n \\
=90(\%)\end{array}$ & $\begin{array}{l}\text { Rebleeding } \\
\text { group } \\
n=32 \text { (\%) }\end{array}$ & $\begin{array}{l}P \\
\text { value }\end{array}$ \\
\hline Yes & $\begin{array}{l}20 \\
(16.4)\end{array}$ & $10(11.1)$ & $10(31.2)$ & \\
\hline No & $\begin{array}{l}102 \\
(83.6)\end{array}$ & $80(88.9)$ & $22(68.8)$ & \\
\hline White blood cells $\left(10^{9} / \mathrm{L}\right)$ & $5.6 \pm 5.2$ & $4.8 \pm 3.6$ & $7.7 \pm 8.0$ & 0.057 \\
\hline Hemoglobin $(g / L)$ & $\begin{array}{l}75.6 \pm \\
17.3\end{array}$ & $76.7 \pm 17.9$ & $72.6 \pm 15.2$ & 0.244 \\
\hline Platelets $\left(10^{9} / \mathrm{L}\right)$ & $\begin{array}{l}80.0 \pm \\
52.5\end{array}$ & $73.7 \pm 45.8$ & $97.5 \pm 65.6$ & 0.066 \\
\hline $\begin{array}{l}\text { Aspartate aminotransferase } \\
\text { (U/L) }\end{array}$ & $\begin{array}{l}45.6 \pm \\
46.0\end{array}$ & $37.8 \pm 26.5$ & $67.6 \pm 74.7$ & 0.034 \\
\hline Albumin $(g / L)$ & $\begin{array}{l}31.2 \pm \\
6.0\end{array}$ & $32.0 \pm 5.8$ & $28.8 \pm 6.1$ & 0.008 \\
\hline Total bilirubin ( $\mu \mathrm{mol} / \mathrm{L})$ & $\begin{array}{l}26.1 \pm \\
29.8\end{array}$ & $21.1 \pm 17.8$ & $39.8 \pm 47.9$ & 0.038 \\
\hline International normalized ratio & $1.3 \pm 0.3$ & $1.3 \pm 0.2$ & $1.5 \pm 0.3$ & $\bowtie 0.001$ \\
\hline Creatinine ( $\mu \mathrm{mol} / \mathrm{L})$ & $\begin{array}{l}65.3 \pm \\
20.8\end{array}$ & $61.1 \pm 15.2$ & $77.1 \pm 28.7$ & 0.005 \\
\hline Etiology of cirrhosis & & & & 0.370 \\
\hline Viral (HBV and/or HCV) & $\begin{array}{l}82 \\
(67.2)\end{array}$ & $62(68.9)$ & $20(62.5)$ & \\
\hline Alcohol & $12(9.8)$ & $10(11.1)$ & $2(6.3)$ & \\
\hline Other & $\begin{array}{l}28 \\
(23.0)\end{array}$ & $18(20.0)$ & $10(31.2)$ & \\
\hline Child-Pugh classification & & & & $\llbracket 0.001$ \\
\hline A & $\begin{array}{l}56 \\
(45.9)\end{array}$ & $47(52.2)$ & $9(28.1)$ & \\
\hline B & $\begin{array}{l}51 \\
(41.8)\end{array}$ & $40(44.5)$ & $11(34.4)$ & \\
\hline
\end{tabular}

*Endoscopic therapy includes variceal band ligation and sclerotherapy.

HBV, hepatitis B virus; HCV, hepatitis C virus; MELD, Model for End-stage Liver Disease; HCC, hepatocellular carcinoma. 


\begin{tabular}{|c|c|c|c|c|}
\hline Characteristics & $\begin{array}{l}\text { All } \\
\text { patients } \\
n=122 \\
(\%)\end{array}$ & $\begin{array}{l}\text { Non-rebleeding group } n \\
=90(\%)\end{array}$ & $\begin{array}{l}\text { Rebleeding } \\
\text { group } \\
n=32(\%)\end{array}$ & $\begin{array}{l}P \\
\text { value }\end{array}$ \\
\hline C & $\begin{array}{l}15 \\
(12.3)\end{array}$ & $3(3.3)$ & $12(37.5)$ & \\
\hline Child-Pugh score (mean \pm SD) & $7.3 \pm 1.8$ & $6.8 \pm 1.4$ & $8.6 \pm 2.3$ & $\bowtie 0.001$ \\
\hline MELD score (mean \pm SD) & $\begin{array}{l}10.8 \pm \\
3.5\end{array}$ & $9.9 \pm 2.7$ & $13.4 \pm 4.0$ & $\varangle 0.001$ \\
\hline Ascites & & & & 0.014 \\
\hline Yes & $\begin{array}{l}50 \\
(41.0)\end{array}$ & $31(34.4)$ & $19(59.4)$ & \\
\hline No & $\begin{array}{l}72 \\
(59.0)\end{array}$ & $59(65.6)$ & $13(40.6)$ & \\
\hline $\mathrm{HCC}$ & & & & 0.052 \\
\hline Yes & $\begin{array}{l}27 \\
(22.1)\end{array}$ & $16(17.8)$ & $11(34.4)$ & \\
\hline No & $\begin{array}{l}95 \\
(77.9)\end{array}$ & $74(82.2)$ & $21(65.6)$ & \\
\hline Hepatic encephalopathy & & & & 0.069 \\
\hline Yes & $\begin{array}{l}18 \\
(14.8)\end{array}$ & $10(11.1)$ & $8(25.0)$ & \\
\hline No & $\begin{array}{l}104 \\
(85.2)\end{array}$ & $80(88.9)$ & $24(75.0)$ & \\
\hline Degree of splenomegaly & & & & 0.603 \\
\hline No/Mild & $\begin{array}{l}62 \\
(50.8)\end{array}$ & $47(52.2)$ & $15(46.9)$ & \\
\hline Moderate/Severe & $\begin{array}{l}60 \\
(49.2)\end{array}$ & $43(47.8)$ & $17(53.1)$ & \\
\hline $\begin{array}{l}\text { Diameter of splenic vein (mean } \pm \\
\text { SD), } \mathrm{mm}\end{array}$ & $\begin{array}{l}10.8 \pm \\
3.3\end{array}$ & $10.6 \pm 3.2$ & $11.2 \pm 3.6$ & 0.449 \\
\hline $\begin{array}{l}\text { Diameter of portal vein (mean } \pm \\
\text { SD), mm }\end{array}$ & $\begin{array}{l}14.5 \pm \\
2.7\end{array}$ & $14.5 \pm 2.5$ & $14.5 \pm 3.1$ & 0.934 \\
\hline Portal vein thrombosis & & & & 0.260 \\
\hline \multicolumn{5}{|c|}{ *Endoscopic therapy includes variceal band ligation and sclerotherapy. } \\
\hline $\begin{array}{l}\text { HBV, hepatitis B virus; HCV, hepatit } \\
\text { hepatocellular carcinoma. }\end{array}$ & virus; 1 & D, Model for End-stage I & Disease; $\mathrm{HCC}$ & \\
\hline
\end{tabular}




\begin{tabular}{|c|c|c|c|c|}
\hline Characteristics & $\begin{array}{l}\begin{array}{l}\text { All } \\
\text { patients }\end{array} \\
n=122 \\
(\%)\end{array}$ & $\begin{array}{l}\text { Non-rebleeding group } n \\
=90(\%)\end{array}$ & $\begin{array}{l}\text { Rebleeding } \\
\text { group } \\
n=32(\%)\end{array}$ & $\begin{array}{l}P \\
\text { value }\end{array}$ \\
\hline Yes & $\begin{array}{l}19 \\
(15.6)\end{array}$ & $16(17.8)$ & $3(9.4)$ & \\
\hline No & $\begin{array}{l}103 \\
(84.4)\end{array}$ & $74(82.2)$ & $29(90.6)$ & \\
\hline Number of varices & & & & 0.298 \\
\hline 1 & $\begin{array}{l}63 \\
(51.6)\end{array}$ & $49(54.4)$ & $14(43.8)$ & \\
\hline$\geq 2$ & $\begin{array}{l}59 \\
(48.4)\end{array}$ & $41(45.6)$ & $18(56.2)$ & \\
\hline Partial splenic embolization & & & & 0.002 \\
\hline Yes & $\begin{array}{l}59 \\
(48.4)\end{array}$ & $51(56.7)$ & $8(25.0)$ & \\
\hline No & $\begin{array}{l}63 \\
(51.6)\end{array}$ & $39(43.3)$ & $24(75.0)$ & \\
\hline \multicolumn{5}{|c|}{ *Endoscopic therapy includes variceal band ligation and sclerotherapy. } \\
\hline $\begin{array}{l}\text { HBV, hepatitis B virus; HCV, he } \\
\text { hepatocellular carcinoma. }\end{array}$ & virus; 1 & , Model for End-stage & Disease; HCC, & \\
\hline
\end{tabular}

A total of were 32 (26.2\%) patients experienced adverse effects following PTVE or PSE including transient upper abdominal pain $(n=23)$, low fever $(n=6)$, and both $(n=3)$, which were minor and alleviated by pharmacologic therapy.

\section{Risk Factors For Rebleeding}

Rebleeding occurred in 32 patients (26.2\%) within the first 3 months after cessation of EVB. The recurrent bleeding was controlled by further pharmacological treatment $(n=6)$, endoscopic therapy $(n=13)$ and TIPS $(n=4)$, while the remaining 9 patients died of massive bleeding $(n=7)$ and hepatic or multiorgan failure $(n=2)$. The cumulative probabilities of presence of variceal rebleeding at $1,2,6$ and 12 months were $9.0 \%, 21.3 \%, 37.4 \%$ and $48.6 \%$, respectively. As uncovered by the univariable analysis, 12 variables of gender, the history of endoscopic therapy, INR, creatinine, AST, albumin, bilirubin, ascites, PSE, MELD score, and Child-Pugh score/classification were markedly correlated with the risk of rebleeding (all $p<$ 0.05). Of note, the Child-Pugh classification and MELD were not further analyzed due to the dependence from Child-Pugh score and the complicated calculation, respectively. In multivariable logistic analysis, a history of endoscopic therapy ( $\mathrm{OR}=4.125 ; 95 \% \mathrm{Cl}$ : $1.208-14.084 ; P=0.024)$, Child-Pugh score (OR = 1.792; 95\% Cl: $1.332-2.411 ; P \otimes 0.001)$, non-PSE (OR $=0.258 ; 95 \% \mathrm{Cl}: 0.085-0.777 ; P=0.016)$ and a 
creatinine $\geq 78 \mu \mathrm{mol} / \mathrm{L}(\mathrm{OR}=7.960 ; 95 \% \mathrm{Cl}: 2.492-25.425 ; P \otimes 0.001)$ were independent risk factors for rebleeding within 3 months (Table 2).

Table 2

Independent risk factors associated with rebleeding as revealed by logistic regression analysis

\begin{tabular}{|c|c|c|c|c|c|}
\hline Variables & B & OR & $95 \% \mathrm{Cl}$ & & $P$ value \\
\hline & & & Lower & Upper & \\
\hline Creatinine ( $\geq 78 \mu \mathrm{mol} / \mathrm{L})$ & 2.074 & 7.960 & 2.492 & 25.425 & $凶 0.001$ \\
\hline Child-Pugh score & 0.583 & 1.792 & 1.332 & 2.411 & $\varangle 0.001$ \\
\hline History of endoscopic therapy* & 1.417 & 4.125 & 1.208 & 14.084 & 0.024 \\
\hline Partial splenic embolization & -1.356 & 0.258 & 0.085 & 0.777 & 0.016 \\
\hline \multicolumn{6}{|c|}{ *Endoscopic therapy includes variceal band ligation and sclerotherapy. } \\
\hline \multicolumn{6}{|c|}{$\mathrm{Cl}$, confidence intervals; OR, odds ratio; $\mathrm{B}, \beta$ coefficient } \\
\hline
\end{tabular}

\section{Development And Validation Of The Nomogram}

A nomogram was developed based on the independent predictors (Fig. 2). In the nomogram, each category of the variables is assigned a score on the Points scale. The sum of these scores is located on the Total Points scale and a line is drawn downward to determine the specific probability of 3-month rebleeding. The score assignment for variables included in the nomogram is summarized in Table 3. 
Table 3

Score assignment for variables included in the nomogram

\begin{tabular}{|c|c|}
\hline Variables & Score \\
\hline \multicolumn{2}{|c|}{ Creatinine $(\mu \mathrm{mol} / \mathrm{L})$} \\
\hline \$78 & 0 \\
\hline$\geq 78$ & 51 \\
\hline \multicolumn{2}{|c|}{ History of endoscopic therapy* } \\
\hline No & 0 \\
\hline Yes & 35 \\
\hline \multicolumn{2}{|c|}{ Partial splenic embolization } \\
\hline No & 33 \\
\hline Yes & 0 \\
\hline \multicolumn{2}{|c|}{ Child-Pugh score } \\
\hline 5 & 0 \\
\hline 6 & 14 \\
\hline 7 & 29 \\
\hline 8 & 43 \\
\hline 9 & 57 \\
\hline 10 & 71 \\
\hline 11 & 86 \\
\hline$\geq 12$ & 100 \\
\hline Total score & 3-month rebleeding probability \\
\hline 49 & 0.1 \\
\hline 69 & 0.2 \\
\hline 82 & 0.3 \\
\hline 93 & 0.4 \\
\hline 103 & 0.5 \\
\hline 113 & 0.6 \\
\hline 124 & 0.7 \\
\hline
\end{tabular}




\begin{tabular}{|ll|}
\hline Variables & Score \\
\hline 137 & 0.8 \\
157 & 0.9 \\
\hline 175 & 0.95 \\
\hline *Endoscopic therapy includes variceal band ligation and sclerotherapy. \\
\hline
\end{tabular}

The nomogram's C-index was 0.85 (95\% Cl: 0.76-0.94) for the cohort, and was confirmed to be 0.83 through bootstrapping validation. Meanwhile, the calibration curve for the probability of rebleeding at 3 months exhibited an excellent agreement between the actual and predicted outcomes (Fig. 3A). The nomogram had higher AUC ( 0.850 vs 0.723 and 0.767 ) and better clinical applicability than the ChildPugh and MELD models (Fig. 3B-C). In addition, the patients were divided into two sets depending on the nomogram scores: low-risk group (0-95 points) and high-risk group (96-219 points). As displayed in the K-M curves, the patients at high risk were more likely to experience rebleeding $(P<0.001)$. (Fig. 3D).

\section{Development Of Webserver}

To facilitate the nomogram's clinical use, an online version is provided at https://jikun.shinyapps.io/rebleeding_of_ev (Fig. 4), which can not only predict personalized rebleeding, but also avoid the manual measurement errors.

\section{Discussion}

Conventional PTVE was introduced in the 1970s for the treatment of EVB, but it has not attracted sufficient attention because of the high rebleeding rate. However, modified PTVE with cyanoacrylate started a new chapter in the management of EVB, which has the high hemostasis and low rebleeding rate due to a more extensive obliteration area and permanent embolization of variceal veins than conventional PTVE ${ }^{16,17}$. A study which compared the modified PTVE and TIPS revealed that variceal rebleeding rates were comparable (30.2\% in TIPS group vs. $20.8 \%$ in PTVE group), and PTVE offered lower incidence of encephalopathy than TIPS ${ }^{18}$, and the similar result was affirmed by Zhang et $\mathrm{al}^{16}$.

In the present study, 122 EVB patients who failed endoscopic therapy underwent modified PTVE with cyanoacrylate as rescue therapy. Because variceal embolization of PTVE only occludes portosystemic shunts but fails to eliminate cirrhosis, new esophagogastric varices are then established as a result of worsening portal hypertension ${ }^{19}$. Our research showed that 32 patients $(26.2 \%)$ developed variceal rebleeding within 3 months after the initial cessation of hemorrhage, which is similar to a 6-week rebleeding rate of $20.8 \%$ after PTVE reported by Zhao et al ${ }^{7}$. 
Most previous studies regarded 6 weeks as an interval for rebleeding according to the Baveno criteria, and excluded seriously ill patients with advanced cirrhosis, HCC and portal thrombosis ${ }^{12,20}$. In our research, a period of 3 months for rebleeding was chosen in view of studies regarding longer-term efficacy of PTVE remain lacking. Further, average waiting time on a list for liver transplantation is approximately 3 months ${ }^{21}$. Risk factors such as advanced cirrhosis, HCC, and portal thrombosis may result in a continuous increase in portal hypertension, making patients more susceptible to early rebleeding ${ }^{22}$. Therefore, we analyzed a group of unselected cirrhotic patients to quantify the risk of rebleeding to identify which patients may need early application of TIPS or liver transplantation and intensive follow-up plan.

Our finding revealed that the rebleeding was noticeably related to the history of endoscopic therapy, ChildPugh score, PSE and creatinine, consistent with the previous reports ${ }^{3,17}$. The Child-Pugh classification only stratifies risk for high, intermediate and low levels, so we selected the Child-Pugh score to quantify an expected probability of rebleeding. The Child-Pugh score is a vital factor reflecting the severity of liver disease in patients with cirrhosis, with every 1-point increase in the Child-Pugh score conferring an $79 \%$ increased risk of rebleeding at 3 months as we discovered. The present study also disclosed that patients with a history of endoscopic therapy were more likely to suffer from rebleeding within 3 months after PTVE. Coincidentally, a retrospective study conducted by Lee et $\mathrm{al}^{23}$ found that $58.3 \%$ patients had early recurrent hemorrhage after banding ligation in cirrhotic patients as well. This relationship could be explained by the extensive mucosal injury surface area and post-banding ulcers caused by the endoscopic therapy ${ }^{23}$. This makes sense since a patient with a history of endoscopic therapy, as a signal of previous EVB, would be at a higher risk of repeated bleeding in such a setting.

Acute renal failure is a severe complication of cirrhosis and a possible harbinger of death ${ }^{24}$, and serum creatinine is a sensitive marker of renal function which acts as a key component of the MELD model. As exhibited in our study, a creatinine $\geq 78 \mu \mathrm{mol} / \mathrm{L}$ is an independent predictor for rebleeding. Augustin $S$ et al proposed creatinine as a crucial marker to identify patients at high risk after an acute variceal hemorrhage $\mathrm{e}^{25}$. It is reported that $24-55 \%$ of patients with end-stage renal disease have increased bleeding complications attributing to the inhibitory influence of uremia on platelet function ${ }^{26}$. It has been demonstrated that PSE appears to be efficacious in reducing episodes of variceal bleeding by reducing the increased portal pressure, as well as improving leukocytopenia and thrombocytopenia caused by hypersplenism ${ }^{10,27}$. In accordance with a controlled study ${ }^{8}$, our findings indicated that rebleeding occurred more frequently in those treated by only PTVE than a combination of PSE and PTVE (38.1\% vs $13.6 \%, p<0.05)$, and no severe complication was observed because we achieved a limited embolization part of middle or lower pole of the spleen, and a limited ratio of $50-70 \%$ of the original splenic volume. Besides, a meta-analysis also demonstrated the dramatic superiority of PSE in preventing recurrent variceal hemorrhage and prolonging overall survival ${ }^{28}$.

To date, only a few studies have identified the value of risk factors in predicting rebleeding after cessation of initial EVB in cirrhotic patients treated by PTVE ${ }^{7,8}$. Nevertheless, those studies failed to establish a 
simple model that could conveniently and accurately predict the probability of rebleeding after PTVE. To the best of our knowledge, this study was the first attempt to develop a predictive nomogram based on the unselected cirrhotic patients with EVB treated by PTVE. Although the MELD model has been proved to be superior to the Child-Pugh model as an index of liver disease severity ${ }^{11}$, the MELD calculation is complex to obtain a score in clinical practice. Therefore, we did not take it into account for the nomogram construction. The nomogram exhibited an accurate prediction for rebleeding with a high $\mathrm{C}$-index of 0.85 , and had superior predictive accuracy and clinical applicability compared with the Child-Pugh and MELD models.

One concern worth highlighting is that our proposed nomogram could be used for early identification of EVB patients who are at a high risk of rebleeding. The rational therapeutic approach should adapt to the different expected risk of rebleeding for each patient; in other words, more aggressive treatments should be administered early for high-risk patients, and unnecessary procedures should be reduced for low-risk patients. As presented in K-M curves, there was a significant correlation between the high-risk patients and the increased probability of rebleeding. We recommend a high-risk patient could be a candidate of an early TIPS or liver transplantation and of an active follow-up plan ${ }^{29}$.

The present study's limitations include its retrospective nature and its single center design. Additionally, HVPG greater than $20 \mathrm{~mm} \mathrm{Hg}$ has been demonstrated previously to be predictive of rebleeding ${ }^{30}$, whereas HVPG was not available in our study since direct measurement of portal hypertension is invasive and inconvenient. Fortunately, Child-Pugh classification could be regarded as an alternative factor because an HVPG above $20 \mathrm{~mm} \mathrm{Hg}$ is equivalent to Child-Pugh grade $\mathrm{C}$ in more than $85 \%$ of patients ${ }^{30}$. The third limitation was a lack of a large cohort of patients from other institutions to verify our nomogram. Although the model requires continued refinement and improvement, its current form may be useful in assisting clinicians to identify the high-risk patients, select optimal treatment protocols, as well as to make clinical decisions and follow-up strategy.

\section{Conclusion}

In conclusion, we developed and validated a creatinine-based model to individually predict the 3-month rebleeding probability in unselected cirrhotic patients with EVB after modified PTVE. Compared with the Child-Pugh and MELD, our nomogram model showed preferable prediction ability and clinical applicability that can help clinicians to discern the high-risk patients so as to perform TIPS or liver transplantation earlier and make intensive follow-up plan for them according to expected probability of recurrent bleeding.

\section{Abbreviations}

EVB Esophagogastric variceal bleeding

PTVE Percutaneous transhepatic variceal embolization 
MELD Model for End-stage Liver Disease

TIPS Transjugular intrahepatic portosystemic shunt

HCC Hepatocellular carcinoma

PSE Partial splenic embolization

INR International normalized ratio

AST Aspartate aminotransferase

C-index Concordance index

ROC Receiver operating characteristic

DCA Decision curve analysis

AUC Area under ROC curve

K-M Kaplan-Meier curve

\section{Declarations}

\section{Availability of data and materials}

All data generated or analysed during this study are included in this article.

\section{Acknowledgement}

The authors thank Dr. Wang for revising the manuscript.

\section{Funding}

This research was supported by the Colleges and Universities Science and Technology Major project Foundation of Henan Province, China (grant number 17A320011).

\section{Contributions}

Study conception and design: ZL. Acquisition of data: KJ, HZ, SZ. Analysis and interpretation of data: KJ, $H Z, X L, P Z, Y S$, SY. Drafting of manuscript: KJ, HZ. Critical revision of manuscript: BX, YZ, PY, ZR, JD, XH. All authors have read and approved the manuscript.

\section{Ethics approval and consent to participate}

This study was approved by the Ethics Committee Board of the First Affiliated Hospital of Zhengzhou University and in accordance with the Declaration of Helsinki (1989) of the World Medical Association. 


\section{Consent for publication}

Written informed consent was obtained from the patients for publication of this work. A copy of the written consents is available for review by the Editor of this journal.

\section{Competing interests}

The authors declare that they have no competing interests.

\section{References}

1.García-Pagán JC, Caca K, Bureau C, et al. Early use of TIPS in patients with cirrhosis and variceal bleeding. N Engl J Med 2010;362(25):2370-2379.

2.Wright AS, Rikkers LF. Current management of portal hypertension. J Gastrointest Surg 2005;9(7):9921005.

3.Wang MT, Liu T, Ma XQ, He J. Prognostic factors associated with rebleeding in cirrhotic inpatients complicated with esophageal variceal bleeding. Chin Med J (Engl) 2011;124(10):1493-1497.

4.Ben-Ari Z, Cardin F, McCormick AP, Wannamethee G, Burroughs AK. A predictive model for failure to control bleeding during acute variceal haemorrhage. J Hepatol 1999;31(3):443-450.

5.Garcia-Tsao G, Sanyal AJ, Grace ND, Carey WD. Prevention and management of gastroesophageal varices and variceal hemorrhage in cirrhosis. Am J Gastroenterol 2007;102(9):2086-2102.

6.Pomier-Layrargues G, Villeneuve JP, Deschênes M, et al. Transjugular intrahepatic portosystemic shunt (TIPS) versus endoscopic variceal ligation in the prevention of variceal rebleeding in patients with cirrhosis: a randomised trial. Gut 2001;48(3):390-396.

7.Zhao JR, Wang GC, Hu JH, Zhang CQ. Risk factors for early rebleeding and mortality in acute variceal hemorrhage. World J Gastroentero/ 2014;20(47):17941-17948.

8.Duan X, Zhang K, Han X, et al. Comparison of percutaneous transhepatic variceal embolization (PTVE) followed by partial splenic embolization versus PTVE alone for the treatment of acute esophagogastric variceal massive hemorrhage. J Vasc Interv Radio/2014;25(12):1858-1865.

9.Bambha K, Kim WR, Pedersen R, Bida JP, Kremers WK, Kamath PS. Predictors of early re-bleeding and mortality after acute variceal haemorrhage in patients with cirrhosis. Gut 2008;57(6):814-820.

10.Zhu K, Meng X, Qian J, et al. Partial splenic embolization for hypersplenism in cirrhosis: a long-term outcome in 62 patients. Dig Liver Dis 2009;41(6):411-416.

11.Wiesner R, Edwards E, Freeman R, et al. Model for end-stage liver disease (MELD) and allocation of donor livers. Gastroenterology 2003;124(1):91-96. 
12.de Franchis R. Revising consensus in portal hypertension: report of the Baveno V consensus workshop on methodology of diagnosis and therapy in portal hypertension. $J$ Hepato/ 2010;53(4):762-768.

13.Wolbers M, Koller MT, Witteman JC, Steyerberg EW. Prognostic models with competing risks: methods and application to coronary risk prediction. Epidemiology 2009;20(4):555-561.

14.Pencina MJ, D'Agostino RB. Overall $\mathrm{C}$ as a measure of discrimination in survival analysis: model specific population value and confidence interval estimation. Stat Med 2004;23(13):2109-2123.

15.Fitzgerald M, Saville BR, Lewis RJ. Decision curve analysis. Jama 2015;313(4):409-410.

16.Zhang K, Sun X, Wang G, et al. Treatment outcomes of percutaneous transhepatic variceal embolization versus transjugular intrahepatic portosystemic shunt for gastric variceal bleeding. Medicine (Baltimore) 2019;98(18):e15464.

17.Wang J, Tian XG, Li Y, et al. Comparison of modified percutaneous transhepatic variceal embolization and endoscopic cyanoacrylate injection for gastric variceal rebleeding. World J Gastroenterol 2013;19(5):706-714.

18.Tian X, Shi Y, Hu J, Wang G, Zhang C. Percutaneous transhepatic variceal embolization with cyanoacrylate vs. transjugular intrahepatic portal systematic shunt for esophageal variceal bleeding. Hepatol Int 2013;7(2):636-644.

19.Tesdal IK, Filser T, Weiss C, Holm E, Dueber C, Jaschke W. Transjugular intrahepatic portosystemic shunts: adjunctive embolotherapy of gastroesophageal collateral vessels in the prevention of variceal rebleeding. Radiology 2005;236(1):360-367.

20.Chen WT, Lin CY, Sheen IS, et al. MELD score can predict early mortality in patients with rebleeding after band ligation for variceal bleeding. World J Gastroenterol 2011;17(16):2120-2125.

21.Everhart JE, Lombardero M, Detre KM, et al. Increased waiting time for liver transplantation results in higher mortality. Transplantation 1997;64(9):1300-1306.

22.Amitrano L, Guardascione MA, Manguso F, et al. The effectiveness of current acute variceal bleed treatments in unselected cirrhotic patients: refining short-term prognosis and risk factors. Am J Gastroenterol 2012;107(12):1872-1878.

23.Lee SW, Lee TY, Chang CS. Independent factors associated with recurrent bleeding in cirrhotic patients with esophageal variceal hemorrhage. Dig Dis Sci 2009;54(5):1128-1134.

24.Cárdenas A, Ginès $P$, Uriz J, et al. Renal failure after upper gastrointestinal bleeding in cirrhosis: incidence, clinical course, predictive factors, and short-term prognosis. Hepatology 2001;34(4 Pt 1):671676. 
25.Augustin S, Altamirano J, González A, et al. Effectiveness of combined pharmacologic and ligation therapy in high-risk patients with acute esophageal variceal bleeding. Am J Gastroenterol 2011;106(10):1787-1795.

26.Lutz J, Menke J, Sollinger D, Schinzel H, Thürmel K. Haemostasis in chronic kidney disease. Nephrol Dial Transplant 2014;29(1):29-40.

27.Koconis KG, Singh H, Soares G. Partial splenic embolization in the treatment of patients with portal hypertension: a review of the english language literature. J Vasc Interv Radiol 2007;18(4):463-481.

28.Wang P, Liu R, Tong L, et al. Partial splenic embolization has beneficial effects for the management of gastroesophageal variceal hemorrhage. Saudi J Gastroenterol 2016;22(6):399-406.

29.Garcia-Pagán JC, Di Pascoli M, Caca K, et al. Use of early-TIPS for high-risk variceal bleeding: results of a post-RCT surveillance study. J Hepatol 2013;58(1):45-50.

30.Abraldes JG, Villanueva C, Bañares R, et al. Hepatic venous pressure gradient and prognosis in patients with acute variceal bleeding treated with pharmacologic and endoscopic therapy. $J$ Hepatol 2008;48(2):229-236.

\section{Figures}




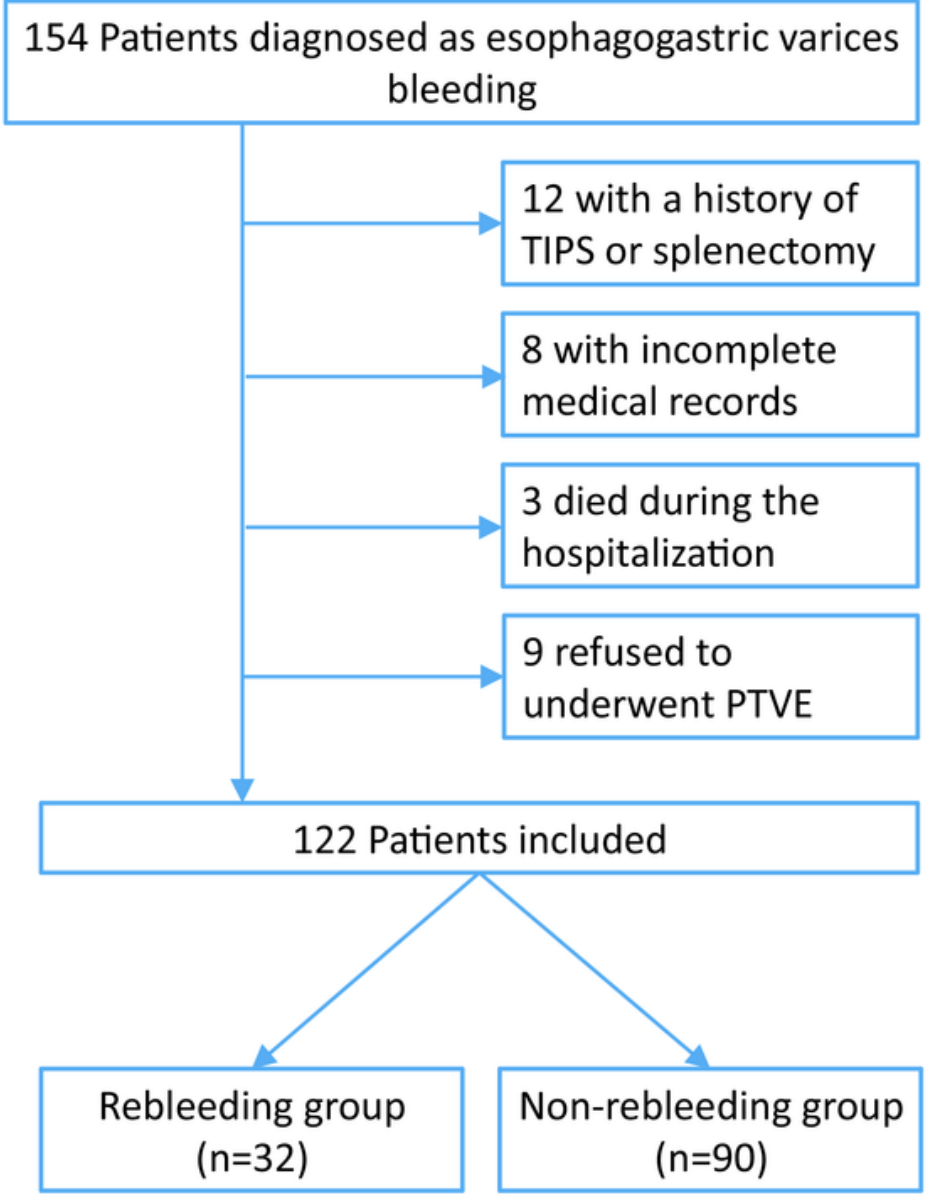

\section{Figure 1}

Flow diagram of the patient selection criteria. TIPS \transjugular intrahepatic portosystemic shunt; PTVE, percutaneous transhepatic variceal embolization. 
Points

History of endoscopic therapy

Creatinine

Partial splenic embolization

Child-Pugh score

Total Points

Risk of rebleeding
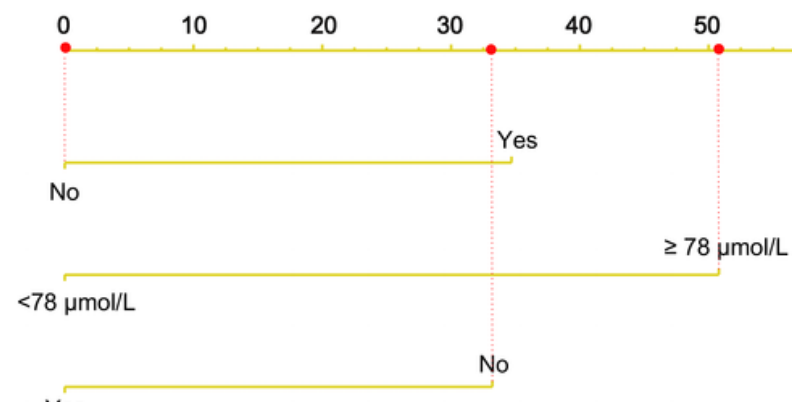

6

8

5

\begin{tabular}{|c|c|c|c|c|c|c|c|c|c|c|c|c|}
\hline & & & & & \multicolumn{8}{|c|}{170} \\
\hline 0 & 20 & 40 & 60 & 80 & 100 & 120 & 140 & 160 & 180 & 200 & 220 & 240 \\
\hline
\end{tabular}

$0.939 \downarrow$

\begin{tabular}{llllllllllll}
\hline 0.05 & 0.1 & 0.2 & 0.3 & 0.4 & 0.5 & 0.6 & 0.7 & 0.8 & 0.9 & 0.95 & 0.99
\end{tabular}

\section{Figure 2}

Nomogram for predicting rebleeding of patients with esophagogastric varices and an example on how to use the nomogram. Each category of the prognostic variables is assigned a score on the Points scale. The sum of these scores is located on the Total points scale and a line is drawn downward to determine the specific probability of 3-month rebleeding. 
A

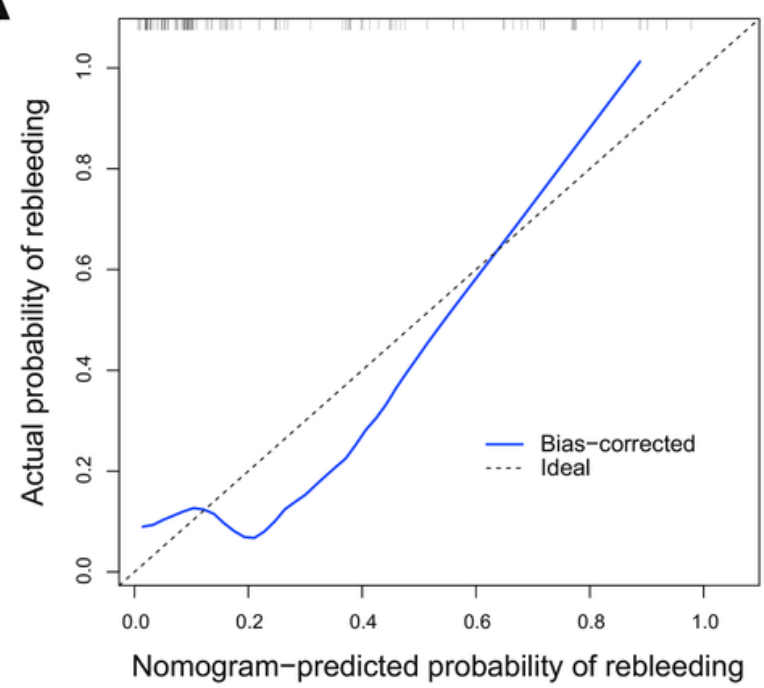

C

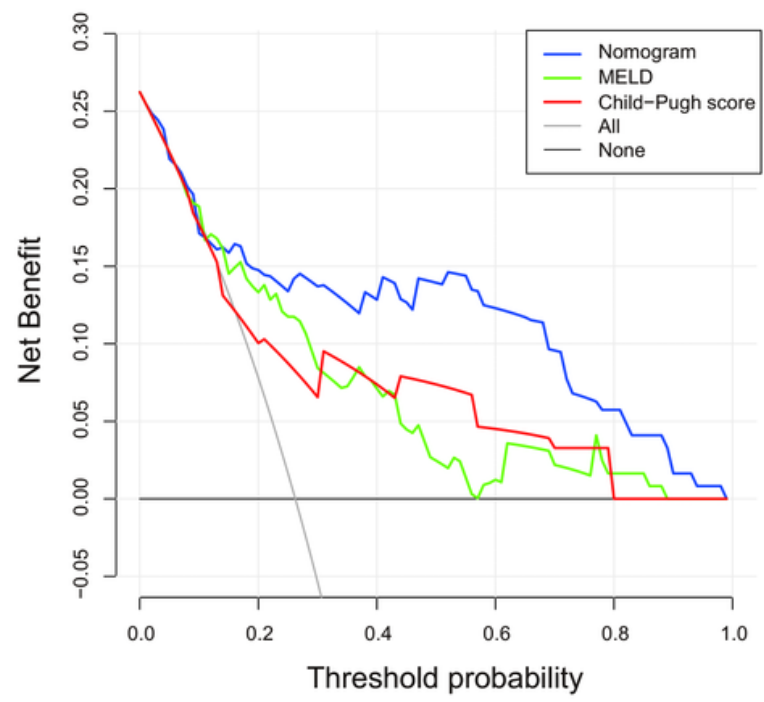

B

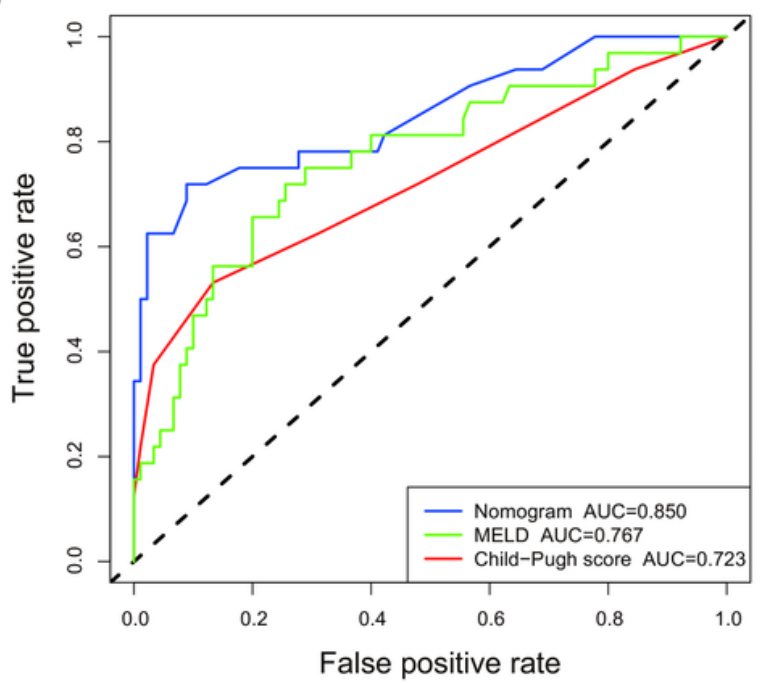

D
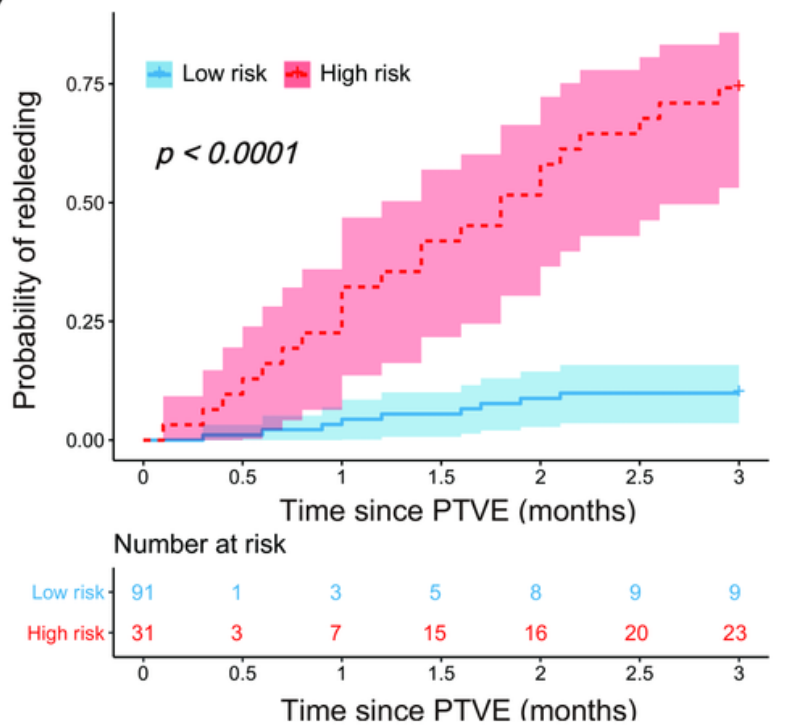

\section{Figure 3}

The validation of the nomogram. (A) calibration curve; (B) ROC curves of the nomogram, MELD and Child-Pugh models; (C) DCA of the nomogram, MELD and Child-Pugh models; and (D) Kaplan-Meier curves of the low-risk and high-risk patients. ROC, receiver operating characteristic curve; AUC, areas under the ROC curve; MELD, the Model for End-stage Liver Disease; DCA, decision curve analysis; PTVE, percutaneous transhepatic variceal embolization. 
Dynamic Nomogram for rebleeding of EV

\begin{tabular}{l} 
History_of_endoscopic_therapy \\
Yes \\
Creatinine \\
$278 \mu$ mol/L \\
Partial_splenic_embolization \\
\hline No \\
Child_Pugh_score \\
5 \\
\hline 5 \\
\hline Set $x$-axis ranges \\
\hline Predict \\
Press Quit to exit the application \\
\hline Quit \\
\hline
\end{tabular}

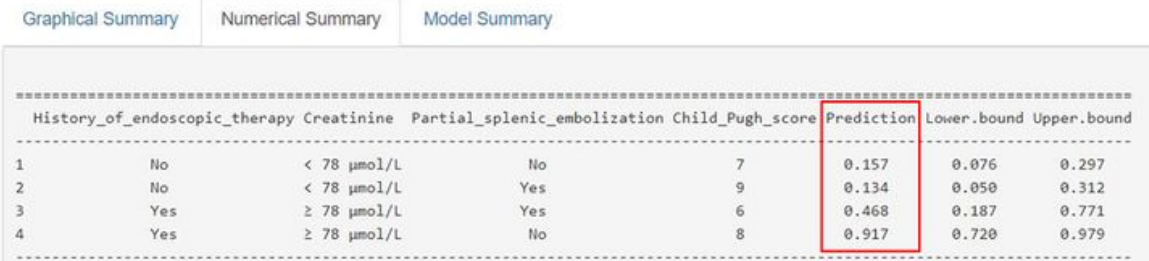

\section{Figure 4}

Layout of an online version of the developed nomogram (https://jikun.shinyapps.io/rebleeding_of_ev). 